\title{
Contemporary evidence-based practice in Canadian emergency medical services: a vision for integrating evidence into clinical and policy decision-making
}

\author{
Jan L. Jensen, MAHSR ${ }^{*}$; Andrew H. Travers, MD, MSc ${ }^{*}$
}

\section{ABSTRACT}

Nationally, emphasis on the importance of evidencebased practice (EBP) in emergency medicine and emergency medical services (EMS) has continuously increased. However, meaningful incorporation of effective and sustainable EBP into clinical and administrative decision-making remains a challenge. We propose a vision for EBP in EMS: Canadian EMS clinicians and leaders will understand and use the best available evidence for clinical and administrative decisionmaking, to improve patient health outcomes, the capability and quality of EMS systems of care, and safety of patients and EMS professionals. This vision can be implemented with the use of a structure, process, system, and outcome taxonomy to identify current barriers to true $\mathrm{EBP}$, to recognize the opportunities that exist, and propose corresponding recommended strategies for local EMS agencies and at the national level. Framing local and national discussions with this approach will be useful for developing a cohesive and collaborative Canadian EBP strategy.

\section{RÉSUMÉ}

On n'a cessé d'insister, à l'échelle nationale, sur l'importance de la pratique fondée sur des données probantes (PFDP) en médecine d'urgence et dans les services médicaux d'urgence (SMU). Toutefois, la véritable incorporation d'une PFDP efficace et durable dans les prises de décision cliniques et administratives pose toujours des problèmes. Aussi nous, les auteurs, proposons-nous la vision suivante de la PFDP dans les $\mathrm{SMU}$ : les cliniciens et les dirigeants en matière de SMU au Canada comprendront les meilleures données probantes qui soient et les appliqueront dans les prises de décision cliniques et administratives afin d'améliorer les résultats cliniques chez les patients, la capacité et la qualité des systèmes de soins des SMU, la sécurité des patients et la compétence des professionnels des $S M U$. Il serait possible de concrétiser cette vision à l'aide d'une taxinomie des structures, des processus, des systèmes et des résultats afin de cerner les obstacles actuels à la véritable PFDP, de discerner les possibilités existantes et de proposer des stratégies recommandées, adaptées aux besoins, aux agences locales de SMU ainsi qu'à des organisations nationales. Ainsi, le fait de dresser un cadre de discussion à l'échelle locale et nationale reposant sur cette approche facilitera l'élaboration d'une stratégie cohérente et collaborative de la PFDP au pays.

$\overline{\text { Keywords: emergency medical services, paramedic, evidence }}$ based practice

\section{INTRODUCTION}

The terms, evidence-based medicine (EBM), evidence-based practice (EBP), and knowledge translation (KT), are familiar to most emergency medicine (EM) and emergency medical services (EMS) clinicians and leaders. There have been calls for meaningful incorporation of these principles into EM and EMS. Several EMS research agendas from around the world have made

From the *Nova Scotia Emergency Health Services, Halifax, NS; and tDepartment of Emergency Medicine, Division of EMS, Dalhousie University, Halifax, NS.

Correspondence to: Jan L. Jensen, 239 Brownlow Avenue, Suite 300, Dartmouth, NS B3B 2B2; Email: jan.jensen@emci.ca 
clear recommendations about the importance of prioritizing and adequately resourcing to enable evidencebased decision-making, ${ }^{1-8}$ with similar calls having been made in EM. ${ }^{9}$ The notion of EBM/EBP/KT is easily appreciated and agreed to; however, meaningful incorporation into clinical and administrative practice in Canadian EMS remains a challenge nationally and at the local EMS system level. This article will propose a vision for Canadian EMS EBP that we can collectively strive to achieve. This vision can be implemented with the use of the structure, process, system, and outcome (SPSO) taxonomy (Figure 1) to identify current barriers and strengths, with corresponding recommended strategies for local EMS agencies and at the national level (Table 1). ${ }^{10}$

\section{THE VISION OF EMS EBP}

Vision statements are used by organizations to describe their long-term objectives; specifically what it is they are aiming for. They describe the future and are stable. ${ }^{11}$ Such an exercise is important for EBP in EMS to increase understanding and engagement among all stakeholders. We propose that the vision is: Canadian EMS clinicians and leaders will understand and use the best available evidence for clinical and administrative decision-making, to improve patient bealth outcomes, the capability and quality of EMS systems of care, and safety of patients and EMS professionals. With this vision set, barriers to achieving it can be identified, current strengths that will propel the vision forward, recognized and effective strategies established (Table 1). ${ }^{12}$

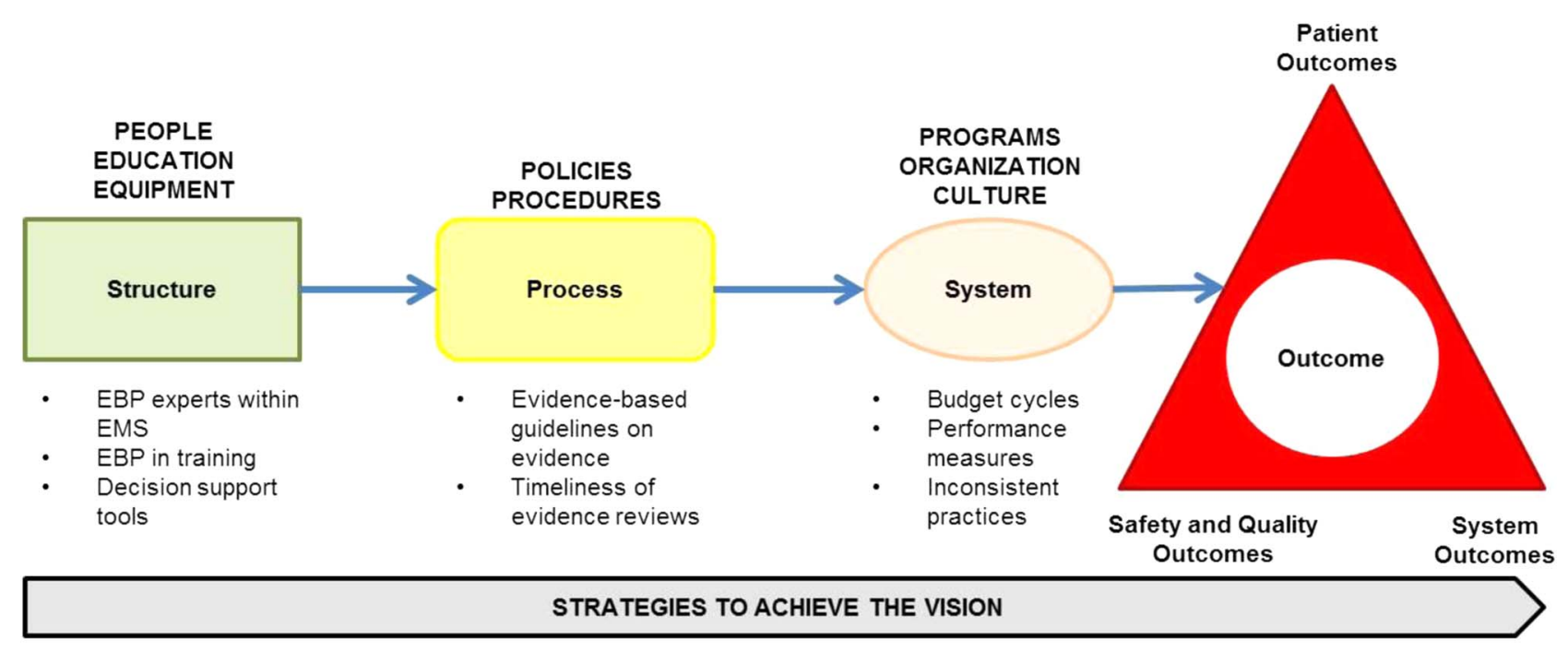

\section{Adapted from $<7>$}

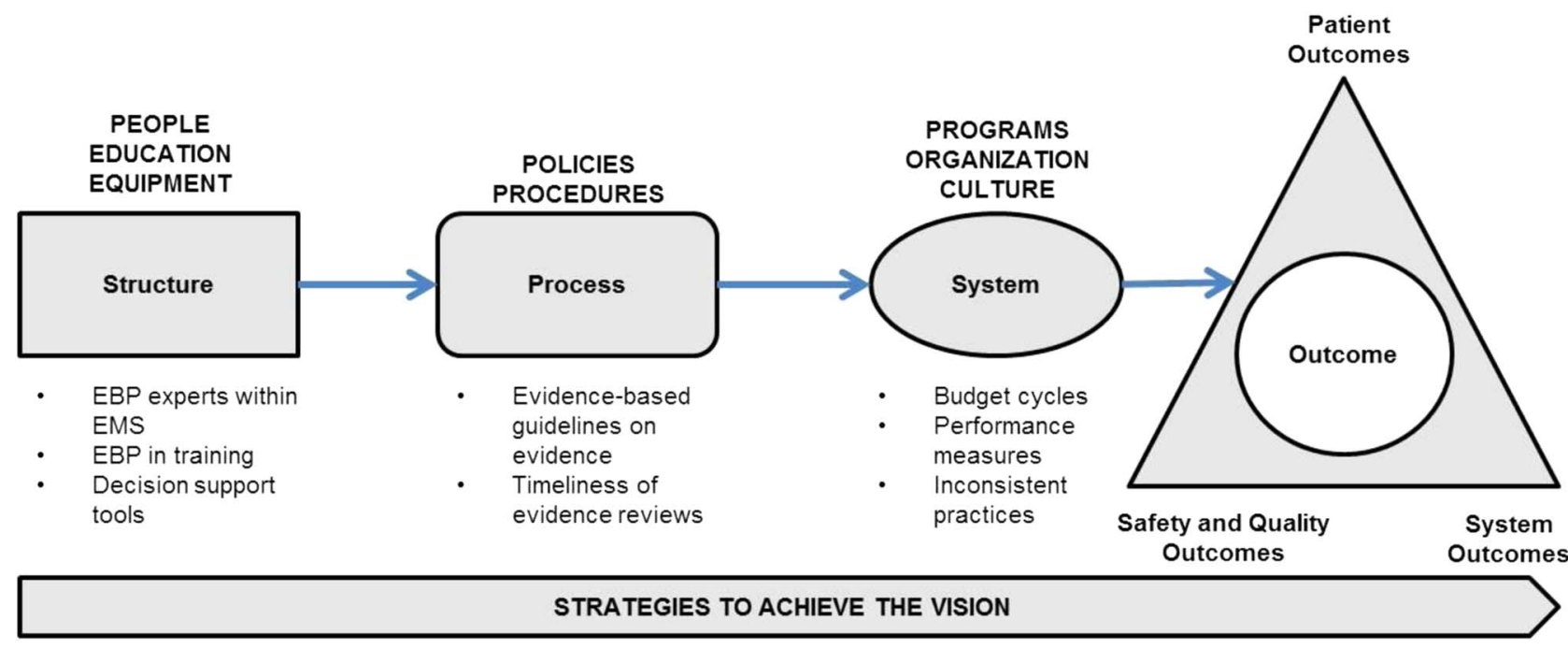

Figure 1. SPSO Strategies to Achieve the Canadian EMS EBP Vision. 
Table 1. Identified barriers and opportunities for incorporating EBP into EMS clinical and policy decision-making

\begin{tabular}{|c|c|c|c|}
\hline Category & Barrier & Existing strengths & National EMS implementation strategy \\
\hline Structures & Few EBP experts in EMS & $\begin{array}{l}\text { Targeted EMS training programs on EBP and for } \\
\text { EMS professionals, including leadership roles. } \\
\text { Some institutions offer EBP services which EMS } \\
\text { could access. }{ }^{33,34} \\
\text { Some EMS agencies employ researchers/research } \\
\text { coordinators/research medical directors. }\end{array}$ & $\begin{array}{l}\text { Optimize development of leadership training that } \\
\text { includes EBP. } \\
\text { Develop ongoing expertise and maintain active } \\
\text { participation in the ILCOR evidence evaluation } \\
\text { process. }{ }^{23,43}\end{array}$ \\
\hline
\end{tabular}

Lack of EBP in foundational and continuing training

Lack of effective and efficient evidence-based decision support tools.

Processes EMS protocols/guidelines/ policies are not based on evidence.

Non-research evidence (e.g., quality improvement, program evaluation data/ findings) are not included in EMS EBP.
Local EMS implementation strategy

Fund EBP training for key staff.

Seek local (non-EMS) expertise and services to

assist with evidence evaluation. Develop

relationship between EMS and academia for this. Implement scholarships for graduate (masters and $\mathrm{PhD}$ ) training for paramedics. ${ }^{44}$

Establish collaborations between EMS services and universities for advanced research training.

Incorporate journal clubs, evidence reviews and

Research is a competency at all paramedic training National organizations to host EBP training levels in Paramedic Association of Canada NOCPs. ${ }^{16}$

Centennial College paramedic program includes research course). ${ }^{45}$

Evidence-based practice is included in a Canadian paramedic textbook. ${ }^{46}$

Training in EBP for paramedics exists (e.g.

Dalhousie University Division of EMS Paramedic Evidence Based Practice ${ }^{47}$ ) and in some settings is required for practicing EMS clinicians (e.g.,

Alberta College of Paramedics literature review module ${ }^{48}$.

Mobile apps and key websites increasingly available National availability of effective tools.

Foster discussion on effective education strategie to meet and exceed NOCP requirements for $\mathrm{EBP}$ in foundational training. research into paramedic continuing training as core curriculum.

Incorporate "journal clubs" and similar scholarly activities into local EMS medical director deliverables.

Regulators/colleges to provide registration credits for EBP continuing education.

Provide updated list of recommended EBP and research apps and websites to EMS clinicians. Provide local EMS quidelines/protocols/policies on an app for EMS clinician use, with links to EBP resources.

GRADE method is well accepted and established. ${ }^{49}$ Establish a working group to development national Evidence reviews are required for protocol and policy change suggestion submissions and is integrated in the process..$^{50,51}$ evidence-based EMS clinical practice guidelines/ protocols, using established methodology. Translate known national and international guidelines (e.g., resuscitation guidelines) to local and national practice.

Showcase programs that effectively include research and non-research evidence in decisionmaking processes.

Refer to available evidence review sources during EMS guideline/protocol/policy update process. Medical Directors and EMS leadership to lead and support incorporation of evidence reviews into policy and protocol changes. Require evidence reviews as part of protocol/policy change suggestion process

Develop local EMS expertise on GRADE or similar guideline development processes.

Review non-research data alongside research evidence during EBP process. 


\begin{tabular}{|c|c|c|c|c|}
\hline Category & Barrier & Existing strengths & National EMS implementation strategy & Local EMS implementation strategy \\
\hline \multirow{5}{*}{ Systems } & $\begin{array}{l}\text { Locating and reviewing } \\
\text { evidence is time } \\
\text { consuming and labour } \\
\text { intensive. }\end{array}$ & $\begin{array}{l}\text { Some EMS systems have access to peer reviewed } \\
\text { journals. Studies are becoming increasingly open } \\
\text { access. } \\
\text { Canadian PEP Project }{ }^{20} \\
\text { Cochrane Prehospital and Emergency Care } \\
\text { systematic reviews. }{ }^{52} \\
\text { Rapid review methods are becoming more } \\
\text { established. } \\
\text { Evidence review services are available in some } \\
\text { sites (e.g., Ottawa and Hamilton. }{ }^{33,34}\end{array}$ & \multirow[t]{2}{*}{$\begin{array}{l}\text { Effective dissemination of EMS-specific evidence } \\
\text { resources, such as PEP. }\end{array}$} & $\begin{array}{l}\text { Incorporate targeted rapid evidence reviews into } \\
\text { guideline/protocol/policy update cycles. } \\
\text { Limit evidence reviews to questions not covered in } \\
\text { existing evidence review sources. }\end{array}$ \\
\hline & $\begin{array}{l}\text { Mismatch of evidence } \\
\text { review cycles and EMS } \\
\text { business cycles. }\end{array}$ & $\begin{array}{l}\text { The timing for release of some EB-guidelines is } \\
\text { predictable; EMS systems can prepare in advance } \\
\text { (e.g., ILCOR/Resuscitation guidelines released } \\
\text { every five years). }{ }^{53}\end{array}$ & & $\begin{array}{l}\text { During business planning, predict funding } \\
\text { requirements for incorporating evidence-based } \\
\text { changes into practice for upcoming cycle. } \\
\text { Budget for cost of EBP (e.g., evidence review } \\
\text { services). }\end{array}$ \\
\hline & $\begin{array}{l}\text { Few effective partnerships } \\
\text { between academia and } \\
\text { EMS service delivery } \\
\text { exist. }\end{array}$ & $\begin{array}{l}\text { Use effective partnerships as a model to implement } \\
\text { in other Canadian sites. }\end{array}$ & $\begin{array}{l}\text { Foster collaboration between EMS and academia } \\
\text { across the country through networks, such as } \\
\text { the Canadian EMS Research Network. }{ }^{54}\end{array}$ & $\begin{array}{l}\text { EMS agencies, universities and research centres } \\
\text { can partner to build the EMS local research } \\
\text { enterprise through: collaborative graduate } \\
\text { programs, industry grant applications, and joint } \\
\text { projects. }\end{array}$ \\
\hline & $\begin{array}{l}\text { Difficult to measure the } \\
\text { impact of EBP in EMS } \\
\text { clinical care/service } \\
\text { delivery. }\end{array}$ & $\begin{array}{l}\text { Evidence-based performance measures established } \\
\text { in the US. }{ }^{40} \\
\text { Benchmarks for specific indicators available in } \\
\text { published guidelines (e.g., time to intervention for } \\
\text { STEMI care). } .^{55,56}\end{array}$ & $\begin{array}{l}\text { Continue national/inter-agency discussion to } \\
\text { develop standards for evidence-based EMS } \\
\text { performance measures. }\end{array}$ & $\begin{array}{l}\text { Incorporate evidence-based performance measures } \\
\text { into local quality improvement processes. }\end{array}$ \\
\hline & $\begin{array}{l}\text { Inconsistency in EBP across } \\
\text { Canadian EMS. }\end{array}$ & $\begin{array}{l}\text { Paramedic Association of Canada NOCPs - } \\
\text { research included as a competency at all } \\
\text { paramedic training levels. } \\
\text { Increasing number of EMS clinicians with research } \\
\text { training. } \\
\text { EBP tools, such as Canadian PEP project. } \\
\text { Structured protocols guide paramedic clinical care in } \\
\text { most EMS systems. }\end{array}$ & $\begin{array}{l}\text { Discussion and projects at national level, though } \\
\text { partnerships and collaboration. } \\
\text { Capitalize on the strengths in the current } \\
\text { widespread use of standardized protocols in } \\
\text { Canadian EMS. Develop national, evidence } \\
\text { based guidelines and protocols that are } \\
\text { implemented at the local level. }\end{array}$ & Prioritize EBP within local services. \\
\hline
\end{tabular}




\section{EMS EBP STRUCTURE}

\section{Structure: barriers}

Structural elements include, but are not limited to, people, equipment, and education. Several structural barriers to the effective incorporation of EBP into EMS practices and clinical care have been identified. The predominant barriers are 1) lack of EBP and research expertise within EMS systems, 2) little or inconsistent training in EBP for clinicians and leaders, and 3) few effective clinical decision support tools that are evidence-based.

To foster the development of EBP expertise among those who work in EMS, foundational training programs for paramedics, physicians, and EMS administration and leadership must include EBP. As in EM, instilling these principles in new graduates enables effective KT. In a recent survey of the Royal College of Physicians and Surgeons of Canada residency directors, key areas of improvement were found to be increasing the number of EBM experts available at sites, incorporating EBM principles into regular learner journal clubs, and nationalization of EBM resources. ${ }^{13}$ Correspondingly, paramedic training needs to incorporate the same principles of EBP throughout the continuum of each program. EMS clinicians (paramedics, physicians, and others) should graduate prepared to locate and use reliable EBP resources. Further work is required to effectively integrate EBP at the EMS point of care with patients. During EMS calls, paramedics and online medical oversight physicians (where applicable) require reliable resources that are simple to navigate and apply. There has been little published on how best to include EBP within clinical decision support tools, and whether they improve clinical care, particularly in the EMS setting. ${ }^{14}$ EMS administrative leaders require EBP skills to incorporate evidence into policy decision-making, an area that requires further specific training and resources. ${ }^{15}$

\section{Structure: strengths and implementation strategies}

Several strengths exist in Canada to improve structures to enable EBP. Some Canadian EMS systems have dedicated research positions, which often provide local EBP expertise. The EBP function can also be embedded into other key positions, such as clinical quality positions, particularly if these staff members receive specific training in this area. Staff members in these positions develop expertise through experience, if their system requires a structured
EBP process for updates to protocols, policies, procedures, and practices (PPPP) to be updated. Research has become a requirement for training at all levels in the Paramedic Association of Canada's National Occupational Competency Profile (NOCP), which helps drive this standard forward ${ }^{16}$ (http://www.paramedic.ca/site/nocp? nav=02). Significant variation in the amount of time and resources invested in EBM likely exists across training programs, but this may continue to improve with national discussions and growing expectations for emphasis to be placed on EBP. Clinical decision support tools are promising. These have the potential to provide evidencebased resources and tools in a concise, easily accessible format. Some Canadian EMS systems have disseminated their local PPPP to staff via smartphone apps. The success of these is a platform to build upon to get EBP tools into the hands of those who need them at the right time. EMS stakeholders must be proactive to make incremental improvements in EBP structure, including expertise, training, and tools. Resources must be allocated in these areas to build a sustainable structure in which EBPs can thrive.

\section{PROCESSES FOR EMS EBP}

\section{Process: barriers}

Process elements include, but are not limited to, PPPP. The leading process barrier is that, in many systems, EMS PPPP are not based on research evidence. This is likely for three main reasons. First, the tendency has been to extrapolate EM knowledge into the EMS realm of practice. ${ }^{17}$ Recently, the evidence flow has been in the inverse direction: high-quality EMS research data have been generalized to the in-hospital setting. ${ }^{18}$ Adapting research findings from the EMS to the EM setting (or vice versa) may work well for some clinical constructs (e.g., stroke, STEMI care in urban locations), and opportunities to do this are limited for others (e.g., rural management of abdominal pain). This is because of a lack of research evidence in some conditions, and also clinical presentation and care differ enough between the settings that generalizing must be done carefully. EMS must continue to work with EM stakeholders in identifying common areas in which EBP/KT efforts can be optimized. Likewise, EM stakeholders must continue to appreciate the nuances of EMS practices.

The second process barrier is the relative lack of research evidence available for EMS care, like the EM 


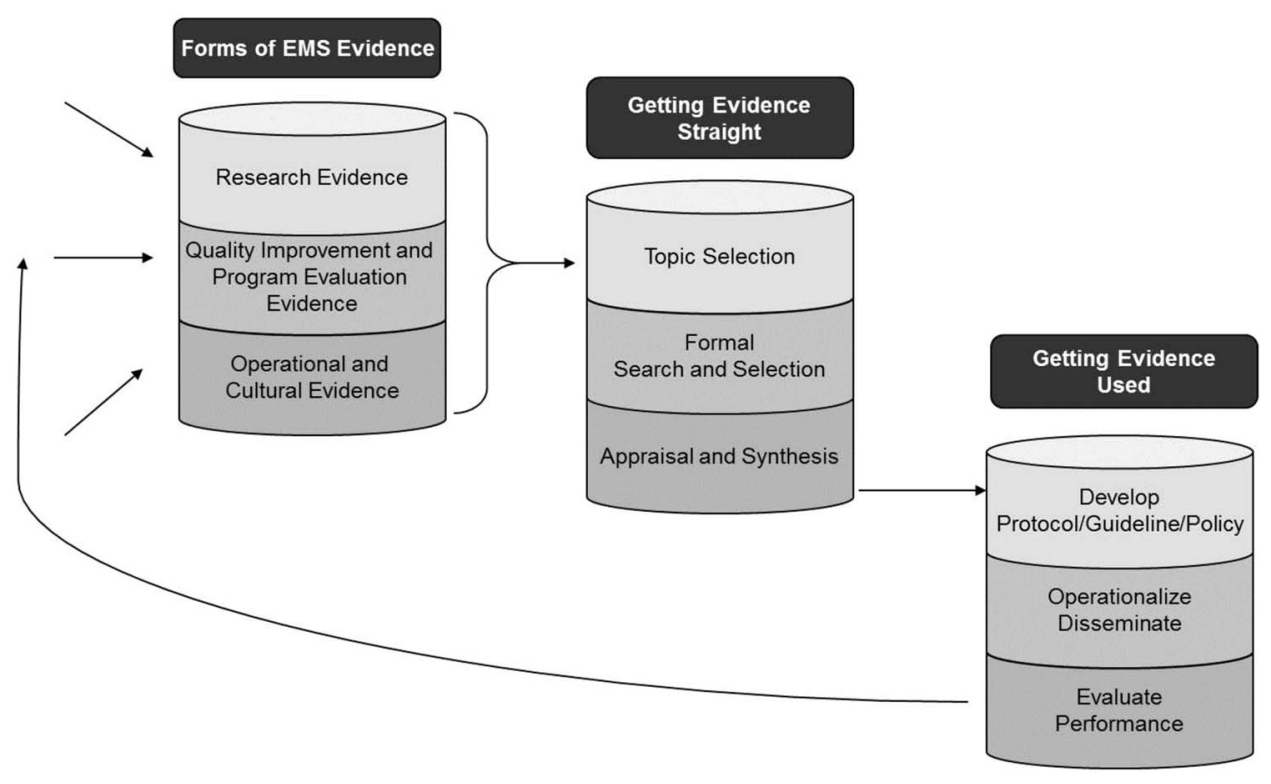

Figure 2. Evidence Evaluation Process in EMS. Adapted from $<1>$.

body of research that is in relative youth compared to hospital-based practices. ${ }^{19}$ This concern is continuously decreasing as the quality and quantity of the EMS evidence base expands rapidly. Of note, much EMS knowledge resides in quality improvement and program evaluation programs. The information derived from these processes should be incorporated into the evidence-based decision-making processes, rather than in separate silos (Figure 2).

The third process barrier is the effort required to identify the evidence and incorporate it into practice. This has been previously well described in the EMS landmark article by Cone; we must first "get the evidence straight" and then "get the evidence used" (see Figure 2). Both parts of this equation can be perplexing to implement and maintain in a meaningful way within Canadian EMS systems. ${ }^{1}$ Translation of evidence from EM to EMS must be done carefully, ${ }^{17}$ because loosely generalized research findings can lead to practices that are no longer evidence-based. The effort required to conduct literature searches, select relevant studies (consciously excluding those that are not), analyse, synthesize, and apply to the breadth of EMS care is immense.

\section{Process: strengths and implementation strategies}

There are a few well established Canadian EMSspecific evidence resources available, including the
Canadian Prehospital Evidence-based Practice (PEP) project (https://emspep.cdha.nshealth.ca/Default.aspx). ${ }^{20}$ Similar programs exist or are in development in Australia $^{21}$ and Ireland ${ }^{22}$ (http://www.ul.ie/cpr/node/ 661). Perhaps the most well-known example of an EBP activity is the resuscitation recommendations that stem from the evidence reviews of the International Liaison Committee on Resuscitation. ${ }^{23}$ Incorporating these resources into EMS guideline development and updating processes is efficient - saving the steps of literature searching, selection, and appraisal. In the United States, a large national project to develop national EMS evidence-based guidelines is underway, ${ }^{24,25}$ and, similarly, the U.S. PEGASUS project is establishing evidence-based guidelines for pediatric $\mathrm{EMS}^{26}$ On a smaller scale, this was explored several years ago in Canada through a small pilot EMS evidence-based guidelines project. ${ }^{27}$

Methodology for conducting evidence reviews is continuously becoming more streamlined and timely. One of the leading approaches for the development of evidence-based guidelines is the Grading of Recommendations, Assessment, Development, and Evaluation (GRADE) methodology, which has been used in several projects, including the U.S. National Evidence-Based Guidelines Project, ${ }^{24}$ the ILCOR evidence review process, ${ }^{28}$ and the development of the Surviving Sepsis International Guidelines. ${ }^{29}$ The AGREE II tool is a robust methodological approach for developing 
evidence-based guidelines. ${ }^{30}$ Efficiently targeting the evidence for specific questions is improving with rapid evidence reviews. ${ }^{31,32}$ Some institutions even offer rapid reviews as a service, such as the Ottawa Hospital Research Institute ${ }^{33}$ and McMaster University Health Forum. ${ }^{34}$ Rapid reviews are often helpful for specific policy and system-level decisions, which may not be addressed through the evidence reviews completed for clinical guidelines. For example, recently, the Nova Scotia provincial government funded a rapid evidence review on collaborative emergency centres to inform decision-making for this program. ${ }^{35}$

EMS stakeholders can use existing EBP processes established within Canada, as well as International EMS systems to advance their local systems. EM and EMS physicians who are in the position of developing and overseeing local practice guidelines need not feel they are alone in their venture. There are several EM and EMS leaders in the country who have gained significant expertise and experience in guideline development using these methods. Using a common and shared framework at the national level for "getting the evidence" and "getting the evidence straight" propels potentially limited local resources for "getting the evidence used." It is essential to incorporate local evidence generated from quality improvement and program evaluation data into EBP. Methods used to generate these findings can be evaluated, and this evidence should be translated to practice and readily available for the end user to consider and use. Finally, EMS systems are grounded in a protocol-driven culture. Traditionally, EMS care and processes have been directive and specific. Although there is a movement towards more open guidelines, the benefit of protocols must not be dismissed. Protocols provide a structured vehicle for many people to perform in the same way, which can enable consistent application of EBPs. EMS must strike a healthy balance between the use of guidelines and protocols. This should be guided through national discussion and identification of best practices.

\section{SYSTEMS FOR EMS EBP}

\section{System: barriers}

System barriers include programs, resources, and the current EMS culture. A recent literature review identified seven publications describing evidence-based approaches and frameworks for EMS clinical policy decision-making. ${ }^{36}$ The summary from this scant literature found that EBP for decision-making is challenging and unlikely to be successful if the efforts were not adequately resourced, which includes funding, expertise, time, and high-level support. A culture that promotes (even demands) EBP and sufficient funding are required to build sustainable programs within EMS systems. This can be challenging because of the asynchronous timing of research (notoriously long), guideline release dates (e.g., resuscitation guidelines released every 5 years in the fall), and operational budget cycles (e.g., usually beginning in the spring). Purposeful inclusion of research, EBP, and anticipated changes to guidelines in business planning strategies would ensure that funding decisions for this are considered. Investment in resources, including developing local EBP expertise and time for EBP activities, can minimize the "knowledge to action" (K2A) gap. ${ }^{37}$ Once evidence is translated or codified into EMS PPPP, efforts must be focused on factors that will enable evidence to be used ${ }^{38}$ and evaluated in an ongoing culture and system of quality (Figure 3).

\section{System: opportunities and implementation strategies}

Effective EMS (and EM) EBP systems are developed and maintained by integrating EBP structure elements (e.g., people trained in EBP with appropriate resources) with EBP process elements (e.g., evidence review of PPPP). Because resources available to EMS for EBP may be limited, it is important for local EMS systems not to "re-invent the wheel" (see Figure 3). If a published high-quality EMS guideline informs the user on "what to do" and "how to do it," which includes the provision of high quality, effective KT tools (e.g., slide sets, pocket guides), the focus should be the development and execution of an effective implementation strategy. If a quality published guideline informs the user on "what to do" but lacks any "how-to" tools, then the priority is to determine how to effectively operationalize the information in the local system in the most meaningful way. There is opportunity here for sharing best practices across EMS systems. If no guideline exists, or the guideline is of low quality, then the focus should be on conducting in-depth evidence appraisal. An effective Canadian EMS EBP system would clearly catalogue the various bodies of knowledge (i.e., clear what/how clinical practice guidelines [CPG] 


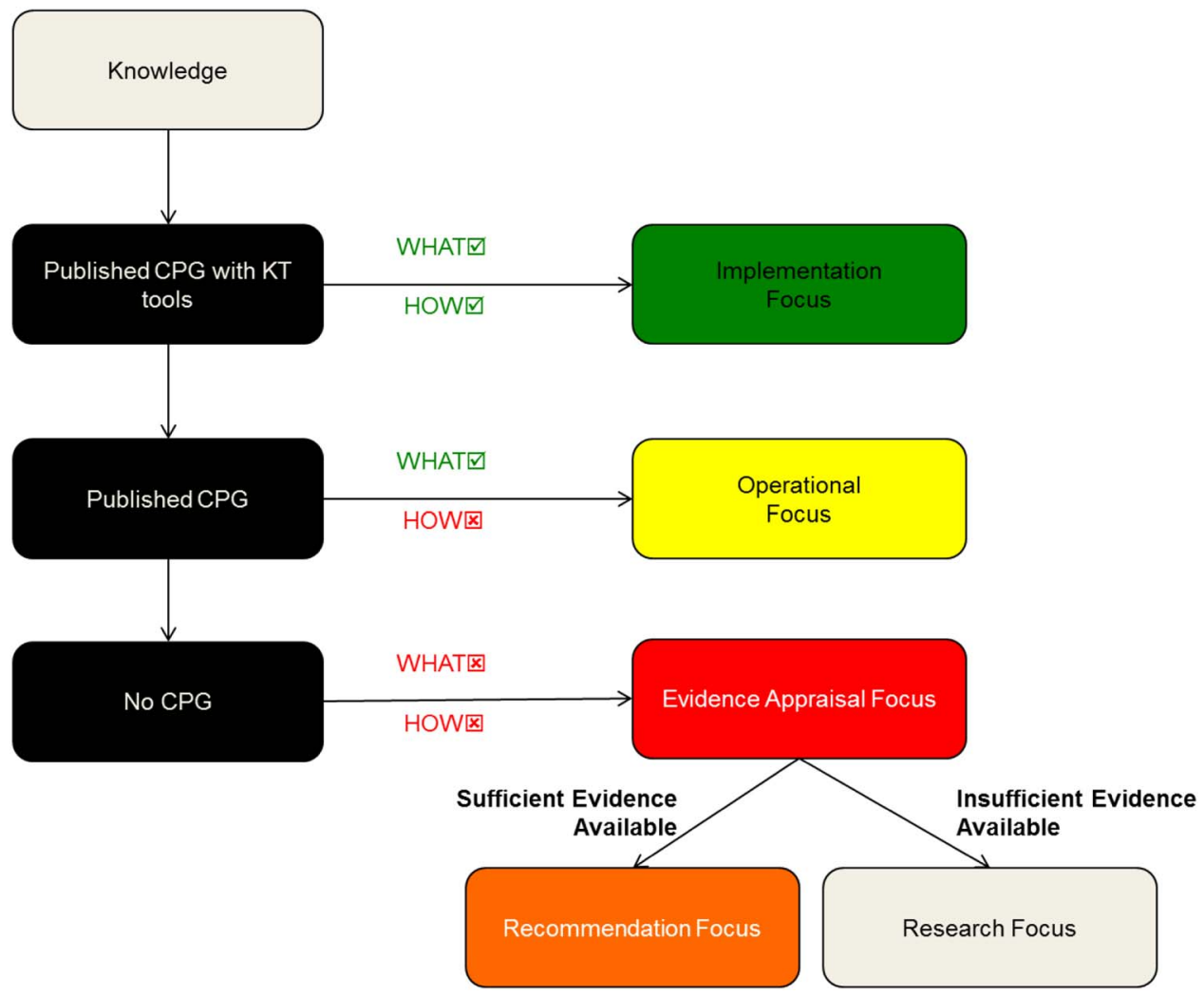

Figure 3. Focus for Action with Availability of Various CPGs.

v. what only CPG, etc.), increasing efficiency for end users when searching for CPG and KT tools.

It is challenging to measure the effect of specific EBP initiatives. Does integrating evidence with clinical and policy decision-making make a difference to important outcomes? Importantly, previous work from the United States proposed EMS performance measures that were grounded in research evidence, ${ }^{39}$ which has been expanded in the recent COMPASS project. ${ }^{40}$ This shifts reliance from traditional performance indicators, such as response times, to indicators that reflect important outcomes, including clinical patient care and safety outcomes. Further research is needed to demonstrate the value of EBP. One study from the United States demonstrated an increase in protocol compliance for appropriate analgesia dosing with the introduction of an evidence-based EMS guideline. ${ }^{41}$ Similar work is needed to demonstrate the effect on other important structure, process, system, and outcomes (SPSOs). ${ }^{10,26}$ As in the process strategies, sharing limited resources at a national/international level to establish the evidence and get it straight with acceptable evidence evaluation tools enables local EMS agencies to optimize resources for "getting it used."

\section{CONCLUSION}

The vision for EBP in Canadian EMS is to use the best available evidence to improve outcomes, including clinical, system, safety, and quality. Achieving meaningful, sustainable practices that incorporate evidence into clinical and policy decision-making can be challenging. Identification of barriers at the structure, process, and system levels enables current opportunities to become clear and targeted implementation strategies to be developed. This approach to improving EBP may be effective at the local EMS level, and the model is also applicable to EM departments and systems. Framing national discussions with this approach will be useful for developing a cohesive and collaborative Canadian strategy.

Acknowledgements: The authors would like to recognize Dr. Alix Carter for her advice in the design and writing of this article. Jan Jensen receives salary support from Emergency Health Services Operations Management, and Dr. Andrew Travers is supported by Emergency Health Services Nova Scotia. The authors would also like to thank the following, for their feedback on Canadian examples of EMS EBP initiatives: Ian Blanchard, Alberta Health Services EMS; Charlene Vacon, 
Alberta Health; Aaron DeRosa, Emergency Health Service Nova Scotia; and Dr. Gina Agarwal, McMaster University.

Competing interests: Academic conflicts include Senior Editor roles for the Dalhousie Canadian Prehospital Evidence-based Practice Project (JLJ) and International Liaison Committee on Resuscitations Committee Basic Life Support co-chair (AHT) and committee member (JLJ).

\section{REFERENCES}

1. Cone DC. Knowledge translation in the Emergency Medical Services: a research agenda for advancing prehospital care. Acad Emerg Med 2007;14(11):1052-7.

2. Sayre MR, White LJ, Brown LH, et al. The national EMS research strategic plan. Prehosp Emerg Care 2005;9(3):255-66.

3. Sayre MR, White LJ, Brown LH, et al. National EMS research agenda: proceedings of the implementation symposium. Acad Emerg Med 2003;10(10):1100-8.

4. Tippett V, Clark M, Woods S, et al. Towards a national research agenda for the ambulance and pre-hospital sector in Australia. 7EPHC 2003;1(1-2):1-8.

5. Snooks H, Evans A, Wells B, et al. What are the highest priorities for research in pre-hospital care? Results of a review and Delphi consultation exercise. 7 Emerg Prim Health Care 2008;6(4):20p.

6. O'Donnell C, O'Reilly S. A national prehospital research strategy. Castletroy, Ireland: Centre for Prehospital Research, University of Limerick \& National Institute of Health Sciences; 2008.

7. Fevang E, Lockey D, Thompson J, et al. Torpo research collaboration. The top five research priorities in physician provided pre-hospital critical care: a consensus report from a European research collaboration. Scand 7 Trauma Resusc Emerg Med 2011;19:57.

8. O'Meara P. Building an Australasian paramedicine research agenda: a narrative review. Health Res Policy Sys 2015;13(1):79.

9. Lang ES, Johnson D. How does "knowledge translation" affect my clinical practice? CFEM 2012;14(3):182-6.

10. Kronick SL, Kurz MC, Lin S, et al. Part 4: systems of care and continuous quality improvement: 2015 American Heart Association guidelines update for cardiopulmonary resuscitation and emergency cardiovascular care. Circulation 2015;132(18 Suppl 2):S397-413.

11. Kantaburta S, Avery GC. The power of vision: statements that resonate. 7 Bus Strategy 2010;31(1):37-45.

12. Williams B, Perillo S, Brown T. What are the factors of organisational culture in health care settings that act as barriers to the implementation of evidence-based practice? A scoping review. Nurse Educ Today 2015;35(2):e34-41.

13. Bednarczyk J, Pauls M, Fridfinnson J, et al. Characteristics of evidence-based medicine training in Royal College of Physicians and Surgeons of Canada emergency medicine residencies - a national survey of program directors. $B M C$ Med Educ 2014;14:57.

14. Hagiwara M. The effect of a Computerised Decision Support System (CDSS) on compliance with the prehospital assessment process: results of an interrupted timeseries study. BMC Med Inform Decis Mak 2014;14:70.
15. Jensen JL, Bigham BL, Blanchard IE, et al. The Canadian National EMS Research Agenda: a mixed methods consensus study. C7EM 2013;15(2):73-82.

16. Paramedic Association of Canada. National occupational competency profile; 2011. Available at: http://paramedic.ca/ nocp/.

17. Bigham B, Welsford M. Applying hospital evidence to paramedicine: issues of indirectness, validity and knowledge translation. CFEM 2015;17(3):281-5.

18. Mausz J, Cheskes S. The impact of prehospital resuscitation research on in-hospital care. CFEM 2015;17(5):551-7.

19. Wright SW, Trott A, Lindsell CJ, et al. Evidencebased emergency medicine. Creating a system to facilitate translation of evidence into standardized clinical practice: a preliminary report. Ann Emerg Med 2008;51(1):80-6; 86.e1-8.

20. Jensen JL, Petrie DA, Travers AH. The Canadian Prehospital Evidence-based Protocols Project: knowledge translation in emergency medical services care. Acad Emerg Med 2009;16(7):668-73.

21. Smith S, Kenneally J. Development and implementation of Victorian prehospital clinical practice guidelines: the supraventricular tachycardia example. Australas 7 Paramed 2013;10(4):unpaginated.

22. University of Limerick Centre for Prehospital Research. The Prehospital Evidence-Based Clinical Practice Guidelines Project; 2015. Available at: http://www.ul.ie/cpr/node/661.

23. Neumar RW, Shuster M, Callaway CW, et al. Part 1: executive summary: 2015 American Heart Association Guidelines Update for Cardiopulmonary Resuscitation and Emergency Cardiovascular Care. Circulation 2015;132(18 Suppl 2):S315-67.

24. Brown KM, Macias CG, Dayan PS, et al. The development of evidence-based prehospital guidelines using a GRADEbased methodology. Prehosp Emerg Care 2014;18(Suppl 1): 3-14.

25. Lang ES, Spaite DW, Oliver ZJ, et al. A national model for developing, implementing, and evaluating evidence-based guidelines for prehospital care. Acad Emerg Med 2012; 19(2):201-9.

26. Maine EMS Medical Direction and Practices Board. Pediatric Evidence-Based Guidelines: Assessment of EMS System Utilization in States (PEGASUS); 2015. Available at: http:// www.maine.gov/ems/documents/WhitePaper_PEGASUS.pdf.

27. Jensen JL, Dobson T, Canadian EMS Quality Improvement Committee. Towards national evidence-informed practice guidelines for Canadian EMS: future directions. Healthc Policy 2011;7(1):22-31.

28. Morrison LJ, Gent LM, Lang E, et al. Part 2: evidence evaluation and management of conflicts of interest: 2015 American Heart Association Guidelines Update for Cardiopulmonary Resuscitation and Emergency Cardiovascular Care. Circulation 2015;132(18 Suppl 2):S368-82.

29. Dellinger RP, Levy MM, Rhodes A, et al. Surviving Sepsis Campaign: international guidelines for management of severe sepsis and septic shock: 2012. Crit Care Med 2013; 41(2):580-637.

30. Brouwers MC, Kho ME, Browman GP, et al. AGREE II: advancing guideline development, reporting, and evaluation in health care. Prev Med 2010;51(5):421-4. 
31. Harker J, Kleijnen J. What is a rapid review? A methodological exploration of rapid reviews in Health Technology Assessments. Int 7 Evid Based Healthc 2012;10(4):397-410.

32. Ganann R, Ciliska D, Thomas H. Expediting systematic reviews: methods and implications of rapid reviews. Implement Sci 2010;5:56.

33. The Ottawa Hospital Research Institute. Knowledge to action; 2014. Available at: http://www.ohri.ca/kta/.

34. McMaster University Health Forum. Rapid Response Program; 2016. Available at: https://www.mcmaster healthforum.org/policymakers/rapid-response-program.

35. Hayden JA, Killian L, Zygmunt A, et al. Methods of a multifaceted rapid knowledge synthesis project to inform the implementation of a new health service model: collaborative emergency centres. Syst Rev 2015;4:7.

36. Muecke S, Curac N, Binks D. Informing clinical policy decision-making practices in ambulance services. Int $\mathcal{F}$ Evid Based Healthc 2013;11(4):299-304.

37. Graham ID, Tetroe J. How to translate health research knowledge into effective healthcare action. Healthc $Q$ 2007;10(3):20-2.

38. Gaddis GM, Greenwald P, Huckson S. Toward improved implementation of evidence-based clinical algorithms: clinical practice guidelines, clinical decision rules, and clinical pathways. Acad Emerg Med 2007;14(11):1015-22.

39. Myers JB, Slovis CM, Eckstein M, et al. Evidence-based performance measures for emergency medical services systems: a model for expanded EMS benchmarking. A statement developed by the 2007 Consortium U.S. Metropolitan Municipalities' EMS Medical Directors. Prehosp Emerg Care 2008;12(2):141-51.

40. National Association of EMS Officials. EMS COMPASS improving systems of care through meaningful measures; 2015. Available at: http://www.emscompass.org/.

41. Hirshon JM, Warner M, Irvin CB, et al. Research using emergency department-related data sets: current status and future directions. Acad Emerg Med 2009;16(11):1103-9.

42. Wright LJ. Introduction. Evidence-based guidelines for prehospital practice: a process whose time has come. Prehosp Emerg Care 2014;18(Suppl 1):1-2.

43. International Liaison Committee on Resuscitation (ILCOR). About ILCOR; 2013. Available at: http://www. ilcor.org/about-ilcor/about-ilcor/ (accessed 30 May 2013).
44. Christie D. From paramedic to 'Dr' for University of Stirling graduate; 2015. Available at: http://www.stir.ac.uk/ health-sciences/newsandevents/news-archive/2015/from paramedictodrforuniversityofstirlinggraduand/.

45. Centennial College. EMS research methods; 2016. Available at: http://www.centennialcollege.ca/programs-courses/fulltime/course/ems-research-methods/.

46. MacDonald RD, Burgess RJ (eds.). Nancy Caroline's emergency care in the streets, 2nd ed Burlington: Jones \& Bartlett; 2013.

47. Dalhousie University, Division of EMS. Paramedic Evidence-Based Practice Program; 2009. Available at: http://emergency.medicine.dal.ca/ehsprotocols/protocols/ ParamedicEBPCourse.cfm.

48. Alberta College of Paramedics. Literature review module; 2014. Available at: https://www.collegeofparamedics.org/ home/continuing-education/mandatory-module-2014.aspx.

49. GRADE working group. Introduction; 2016. Available at: http://www.gradeworkinggroup.org/intro.htm\#criteria.

50. Emergency Health Services. Developing clinical practice guidelines $6154.03 ; 2001$. Available at: http://novascotia.ca/ dhw/ehs/documents/policies/6154.03.pdf.

51. Alberta Health Services EMS. EMS medical control protocols; 2016. Available at: http://www.albertahealthservices. ca/info/page3165.aspx.

52. Cochrane Prehospital and Emergency Care. About us; 2016. Available at: http://pec.cochrane.org/about-us.

53. Bigham BL, Aufderheide TP, Davis DP, et al. Knowledge translation in emergency medical services: a qualitative survey of barriers to guideline implementation. Resuscitation 2010;81(7):836-40.

54. Canadian EMS Research Network. About us; 2016. Available at: http://cern-rcrsp.ca/about-us/.

55. O'Connor RE, Al Ali AS, Brady WJ, et al. Part 9: acute coronary syndromes: 2015 American Heart Association Guidelines Update for Cardiopulmonary Resuscitation and Emergency Cardiovascular Care. Circulation 2015; 132(18 Suppl 2):S483-500.

56. O'Gara PT, Kushner FG, Ascheim DD, et al. 2013. ACCF/ AHA Guideline for the Management of ST-Elevation Myocardial Infarction. A report of the American College of Cardiology Foundation/American Heart Association Task Force on Practice Guidelines. $7 \mathrm{Am}$ Coll Cardiol 2013;61(4):e78-140. 